\title{
Qualidade de frutos ensacados em diferentes genótipos de macieira
}

\author{
The quality of bagged fruit of different apple genotypes
}

\author{
Janaína Pereira dos Santos ${ }^{\mathrm{I}}$ Anderson Fernando Wamser ${ }^{\mathrm{II}}$ Frederico Denardi ${ }^{\mathrm{II}}$
}

\section{RESUMO}

Este trabalho teve como objetivos verificar se o ensacamento e a retirada das embalagens em diferentes épocas afetam a qualidade dos frutos de diferentes genótipos de macieira. O estudo foi conduzido em pomar orgânico de maçãs, na Epagri/Estação Experimental de Caçador, SC, durante a safra 2005/06, com as cultivares "Fuji Suprema” e "Royal Gala” e com as seleções M-11/00, M-13/00 e MR-11/90. Utilizou-se o delineamento completamente ao acaso, composto por cinco repetições, sendo que cada planta constituiu uma repetição, e desta ensacaram-se todos os frutos. Os tratamentos foram compostos por três épocas de retirada das embalagens (15 e sete dias antes da colheita e na colheita); dois tipos de embalagens (saco de papel manteiga parafinado branco $e$ saco de polipropileno microperfurado transparente); e o controle (frutos não ensacados). Avaliaram-se diâmetro, peso, maturação através da cor de fundo, russeting e queimadura pelo sol. Verificou-se que o ensacamento pode influenciar o tamanho e o peso de frutos em relação aos frutos não ensacados. O tipo de embalagem e o maior tempo de permanência destas nos frutos podem afetar a maturação. Não houve nenhum efeito do ensacamento ou do tipo e época de embalagem sobre a incidência de "russeting". A embalagem de polipropileno microperfurado transparente propiciou em "Fuji Suprema”, "Royal Gala” e "MR-11/90” mais queimaduras de frutos em relação à embalagem de papel manteiga parafinado e ao tratamento controle.

Palavras-chave: Malus domestica, coloração de frutos, fruticultura de clima temperado.

\section{ABSTRACT}

This study is aimed at evaluating the effect of unbagging during different periods on the quality of the fruits of apple genotypes. The study was carried out in an organic apple orchard, at Epagri/Caçador Experimental Station, SC, during the 2005/06 season, with cv. 'Fuji Suprema' and 'Royal Gala' and the selections $M-11 / 00, M-13 / 00$ and MR-11/90. The experiment was conducted under completely randomized block design with five repetitions, and each plant constituted a repetition. All the fruits of each repetition were bagged. The treatments were composed by three different periods of unbagging (15 and seven days before harvest and at harvest); two different bag materials (paraffinated butter white paper bags and transparent polypropylene microperfurated bags); and the control (unbagged fruits). They were evaluated in size, weight, maturation through the ground color, russeting and burning by the sun. It was verified that the bagging can influence the size and the weight of the fruits in relation to the unbagged fruits (control). The type of the packing and the longest time of permanence of these packings in the fruits can affect the maturation. It was not observed any effect of the bagging or of the type of the packing and the packing time on the russeting. The transparent polypropylene microperfurated bag propiated in some genotypes more burns of fruits in relation to paraffinated butter white paper bag and the treatment control.

Key words: Malus domestica, fruit color, temperate-zone fruits.

\section{INTRODUÇÃO}

Em 2005, a produção mundial de maçãs foi de 63,4 milhões de toneladas, sendo que o Brasil ocupou o décimo quarto lugar entre os maiores produtores dessa fruta, com 870 mil toneladas, representando 1,33\% da produção total (FAO, 2006).

\footnotetext{
'Laboratório de Entomologia, Empresa de Pesquisa Agropecuária e Extensão Rural de Santa Catarina (EPAGRI)/Estação Experimental de Caçador. Rua Abílio Franco, CP 591, 89500-000, Caçador, SC, Brasil. E-mail: janapereira@epagri.sc.gov.br. Autor para correspondência.

IEPAGRI/Estação Experimental de Caçador, SC, Brasil. 
Concentrada na região Sul, a maior parte da produção brasileira provém das cultivares "Gala” e "Fuji” e de mutações destas (ABPM, 2004; ALMEIDA \& ALVES, 2006). A preferência por essas cultivares e suas mutações se deve ao critério de escolha do consumidor por frutos mais coloridos, de boa aparência, seguido pelo sabor e pela capacidade de conservação frigorífica da fruta (ALMEIDA \& ALVES, 2006).

A qualidade da fruta é um fator importante para se obter melhores oportunidades por preços maiores (ALMEIDA \& ALVES, 2006). O que determina esta qualidade é a avaliação de alguns atributos, como coloração, formato, aroma, sabor, valor nutritivo, constituintes químicos e propriedades funcionais (ABBOT, 1999).

No caso da coloração, quanto mais vermelho o fruto, mais valorizado será (ALMEIDA \& ALVES, 2006), sendo que os vermelho-rajados sobre fundo amarelo são os mais preferidos (CAMILO \& DENARDI, 2006) e o formato arredondado é preferido ao achatado (ALMEIDA\&ALVES, 2006).

Em maçãs vermelhas com presença de antocianina, a cor de fundo tem efeito marcante sobre a aparência do fruto. Esta cor de fundo é bastante variável, desde o verde-escuro, como na "Granny Smith”, até branco-creme, da “Anna”. A cor de fundo mais freqüente é a amarela, que forma o fundo da maioria das cultivares comerciais, dentre elas a "Gala”, a "Daiane”, a "Jonagold”, a "Elstar" e a "Sansa”. Em geral, quanto mais verde-escura a cor de fundo sobreposta por vermelho da antocianina, mais escura a aparência da fruta. As maçãs mais atraentes apresentam cor de fundo na faixa do amarelo para o branco-creme. O ensacamento com embalagens opacas tem efeito marcante no clareamento deste fundo, resultando em maçãs mais atrativas, recurso bastante usado em países como o Japão e a China (DENARDI, informação pessoal).

Os distúrbios fisiológicos estão entre os fatores que podem provocar depreciação na aparência dos frutos e modificar o sabor da polpa, reduzindo, conseqüentemente, o valor comercial da fruta in natura (SANTOS \& WAMSER, 2006). O russeting é um importante distúrbio fisiológico, por deixar áspera e de coloração ferruginosa a epiderme dos frutos, depreciando a classificação do produto e diminuindo o seu valor (BASSO, 2006).

No sistema de produção orgânica de maçãs, o ensacamento dos frutos pode ser uma alternativa para o controle de doenças e insetos-praga, principalmente a mosca-das-frutas (Anastrepha fraterculus), sem afetar a qualidade, preservando a aparência e o preço de mercado (SANTOS \&
WAMSER, 2006). O ensacamento de frutos de pêra japonesa é realizado para evitar danos de pássaros, insetos-praga, doenças, russeting, diminuir o número de aplicações e a quantidade de defensivos químicos, amenizar danos ocasionados por chuvas leves de granizo, vento e melhorar a aparência de os frutos (FAORO, 2001; PETRI et al., 2001).

O ensacamento proporciona melhoria na qualidade organoléptica dos frutos. Apesar dos custos de produção serem maiores, há um nicho de mercado que prioriza a qualidade sanitária à visual e que se dispõe a remunerar melhor produtos orgânicos, resultando em boa compensação dos altos custos de produção (FAORO, 2004).

Neste contexto, este trabalho teve como objetivos verificar se o ensacamento e a retirada das embalagens em diferentes épocas afetam a qualidade dos frutos de diferentes genótipos de macieira.

\section{MATERIAL E MÉTODOS}

O estudo foi conduzido em pomar de produção orgânica de maçãs, na Epagri/Estação Experimental de Caçador, SC. O pomar, situado a 1.000m de altitude, está localizado no município de Caçador, SC ( $26^{\circ} 41^{\prime}$ 'S e $\left.51^{\circ} \mathrm{W}\right)$, região fisiográfica do Vale do Rio do Peixe. O clima da região é temperado constante úmido, com verões amenos, do tipo $\mathrm{Cfb}$, conforme a classificação de Köepen (PANDOLFO et. al., 2002). As médias da temperatura do ar e da precipitação pluviométrica total anual foram de $17^{\circ} \mathrm{C}$ e $1.624 \mathrm{~mm}$, respectivamente.

O experimento foi conduzido em um pomar de aproximadamente 0,6 ha, com plantas de três anos, distribuídas no espaçamento de 4,5m entre linhas e de $1,5 \mathrm{~m}$ entre plantas, formado pelas cultivares "Fuji Suprema”, "Royal Gala” e “Catarina” e por sete seleções de macieira. Neste estudo, estudaram-se as cultivares “Fuji Suprema” (grupo “Fuji”) e "Royal Gala” (grupo “Gala”) e as seleções M-11/00, M-13/00 (grupo “Gala”) e MR-11/90 (grupo “Fuji”).

Utilizou-se o delineamento experimental completamente ao acaso, composto por cinco repetições, sendo que cada planta constituiu uma repetição, da qual foram ensacados todos os frutos. Os tratamentos foram compostos por três épocas de retirada das embalagens (15 e sete dias antes da colheita e na colheita); dois tipos de embalagens (saco de papel manteiga parafinado branco, de 13,2cm x 22,2cm, e saco de polipropileno microperfurado transparente, de 17,0cm x 20,0cm); e o controle (frutos não ensacados). Ensacaram-se os frutos quando estes apresentavam em média 20mm de diâmetro. 
As avaliações da frutificação efetiva, ou seja, as determinações do número de frutos fixados por cacho floral, indicaram em média por planta: 5,7 frutos na "Fuji Suprema”; 8,7 na "Royal Gala”; 12,6 na M-11/00; 11,6 na M-11/90 e 19 na M-13/00. Os frutos de "Royal Gala”, M-11/00, M-13/00, MR-11/90 e "Fuji Suprema” foram colhidos, respectivamente em: 14/02; 16/03; 29/03; 05/04 e 18/04 de 2006.

Após a colheita, os frutos foram acondicionados em sacos plásticos e armazenados em câmara frigorífica $\left(1^{\circ} \mathrm{C} \pm 1^{\circ} \mathrm{C}\right)$ até a data das avaliações. $\mathrm{Na}$ avaliação, foram utilizados todos os frutos ensacados, verificando-se diâmetro, peso, maturação através da cor de fundo, russeting e queimadura pelo sol.

Para avaliar o peso dos frutos, utilizou-se balança de precisão, e para avaliar o tamanho, utilizouse paquímetro digital, medindo-se o diâmetro transversal dos frutos.

A maturação foi medida pela avaliação da cor de fundo da epiderme dos frutos, conforme tabela estabelecida para cada grupo, "Gala" e "Fuji" (ARGENTA, 2004a;b). A tabela de cores para o grupo “Gala” é composta pelos seguintes índices: (1 ou 1a)frutas imaturas; (2 ou 2a)- início de maturação, índice de amido entre 2,0 e 3,0; (3 ou 3a)- ponto de colheita para longos períodos de armazenagem, índice de amido entre 3,0 e 5,5, firmeza da polpa entre 17 e 19lb, sólidos solúveis totais (SST) entre 10,5 e 12\%; (4 ou 4a)- frutas maduras, ideais para consumo ou para curtos períodos de armazenagem, índice de amido entre 5,5 e 8,0; (5 ou 5a)- frutas muito maduras, baixa qualidade de textura (ARGENTA, 2004a). De acordo com ARGENTA(2004b), a tabela de cores para o grupo "Fuji” é composta pelos seguintes índices: (1 ou 1a)- frutas imaturas; (2 ou 2a)início de maturação, índice de amido entre 2,0 e 3,0; (3 ou 3a)- ponto de colheita para longos períodos de armazenagem, índice de amido entre 4,0 e 6,0, firmeza da polpa entre 16 e 18lb, SST entre 13 e 14,5\%; (4 ou 4a)- frutas maduras, ideais para consumo ou para curtos períodos de armazenagem, índice de amido entre 6,5 e 8,0; (5 ou 5a)- frutas muito maduras, baixa qualidade de textura.

A percentagem de frutos com russeting e com queimadura pelo sol foi avaliada visualmente, quando estes apresentavam pelo menos uma mancha do dano na epiderme.

Os resultados obtidos foram submetidos à análise de variância pelo teste F. Quando houve significância estatística, os tratamentos foram comparados entre si pelo teste de Tukey a 5\% de probabilidade de erro.

\section{RESULTADOS E DISCUSSÃO}

\section{Diâmetro dos frutos}

O diâmetro de frutos foi influenciado pelo tipo de embalagem utilizada no ensacamento, porém isso variou em função da época de retirada da embalagem. Para a cv. "Royal Gala” e para a seleção MR-11/90, não houve diferenças significativas, independentemente do tipo de embalagem; já para a cv. "Fuji Suprema”, os frutos desensacados na colheita com embalagem de papel manteiga parafinado apresentaram tamanho maior que os do tratamento controle. Na seleção M-13/00, foram maiores os frutos retirados aos sete dias antes da colheita, independentemente do tipo de embalagem. Porém, os efeitos sobre o diâmetro parecem ter sido maiores na seleção $M-11 / 00$, na qual os frutos apresentaram tamanho maior que os do tratamento controle quando a embalagem foi retirada aos sete dias antes da colheita e na colheita, independentemente do tipo de embalagem (Tabela 1). Em termos gerais, o ensacamento resultou em aumento máximo de 17, 18 e 9\% para a cv. "Fuji Suprema” e para as seleções M-11/00 e M-13/00, respectivamente.

Frutos com tamanho inferior a $65 \mathrm{~mm}$ e superior a 85mm de diâmetro são comercializados por preços mais baixos no mercado brasileiro. Para exportação, principalmente para países europeus e para os Estados Unidos, há uma preferência por frutos que fiquem nesta faixa de tamanho (CAMILO \& DENARDI, 2006). De acordo com a tabela 1 , apenas os frutos ensacados de "Fuji Suprema” e de MR-11/90 não apresentaram tamanho inferior a 65mm.

Peso dos frutos

Para peso de frutos, não houve efeito do ensacamento na cv. "Royal Gala” e na seleção MR-11/ 90. Analisando-se por genótipo, na cv. "Fuji Suprema”, apenas no tratamento com polipropileno microperfurado retirado aos 15 dias antes da colheita, os frutos apresentaram peso inferior aos do tratamentocontrole. Na seleção M-13/00, tiveram influência significativa no aumento do peso dos frutos o ensacamento com papel manteiga parafinado retirado aos 15 dias antes da colheita e com o polipropileno microperfurado retirado aos sete dias. No entanto, os maiores efeitos do ensacamento no peso médio dos frutos foram observados na seleção $M-11 / 00$, na qual tanto o papel manteiga parafinado, quanto o polipropileno microperfurado, induziram maior peso médio de frutos em relação aos do tratamento-controle, independentemente da época de retirada da embalagem (Tabela 1). 
Tabela 1 - Diâmetro e peso de frutos de diferentes genótipos de macieira em função do tipo de embalagem utilizada no ensacamento e da época de desensacamento.

\begin{tabular}{|c|c|c|c|c|c|}
\hline \multirow{2}{*}{ Tratamentos } & Fuji Suprema & Royal Gala & M-11/00 & M-13/00 & MR-11/90 \\
\hline & \multicolumn{5}{|c|}{ Diâmetro dos frutos (mm) } \\
\hline \multicolumn{6}{|l|}{ Papel manteiga parafinado branco } \\
\hline 15 dias antes da colheita & $72,1 \mathrm{ab}^{1}$ & $61,1^{\mathrm{ns}}$ & $61,1 \mathrm{ab}^{1}$ & $61,6 a b^{1}$ & $71,1^{\mathrm{ns}}$ \\
\hline 7 dias antes da colheita & $69,3 \mathrm{ab}$ & 60,5 & 64,6 a & 63,6 a & 69,2 \\
\hline Dia da colheita & 74,6 a & 64,1 & 64,6 a & $60,8 \mathrm{ab}$ & 68,1 \\
\hline \multicolumn{6}{|c|}{ Polipropileno microperfurado transparente } \\
\hline 15 dias antes da colheita & $64,8 \mathrm{~b}$ & 61,0 & $60,9 \mathrm{ab}$ & $60,0 \mathrm{ab}$ & 68,0 \\
\hline 7 dias antes da colheita & $66,8 \mathrm{ab}$ & 62,6 & 65,5 a & 63,4 a & 67,5 \\
\hline Dia da colheita & $69,9 \mathrm{ab}$ & 62,3 & $62,7 \mathrm{a}$ & $61,0 \mathrm{ab}$ & 68,0 \\
\hline Controle (frutos não ensacados) & $63,7 \mathrm{~b}$ & 59,2 & 54,7 b & 58,4 b & 64,9 \\
\hline Média & 68,7 & 61,5 & 62,0 & 61,2 & 68,1 \\
\hline \multirow[t]{2}{*}{ CV (\%) } & 7,7 & 5,4 & 7,2 & 4,4 & 5,0 \\
\hline & \multicolumn{5}{|c|}{ Peso médio dos frutos (g) } \\
\hline \multicolumn{6}{|l|}{ Papel manteiga parafinado branco } \\
\hline 15 dias antes da colheita & 178,6 a & $113,2^{\mathrm{ns}}$ & 123,2 a & 109,0 a & $148,3^{\text {ns }}$ \\
\hline 7 dias antes da colheita & $145,7 \mathrm{ab}$ & 117,7 & 138,4 a & $108,2 \mathrm{ab}$ & 140,3 \\
\hline Dia da colheita & 176,4 a & 131,2 & 144,4 a & $100,7 \mathrm{ab}$ & 134,1 \\
\hline \multicolumn{6}{|c|}{ Polipropileno microperfurado transparente } \\
\hline 15 dias antes da colheita & $118,8 \mathrm{~b}$ & 113,2 & 116,6 a & $99,0 \mathrm{ab}$ & 133,2 \\
\hline 7 dias antes da colheita & $141,6 \mathrm{ab}$ & 122,0 & 143,8 a & 113,3 a & 131,9 \\
\hline Dia da colheita & $159,7 \mathrm{ab}$ & 118,7 & 124,7 a & $101,1 \mathrm{ab}$ & 136,0 \\
\hline Controle (frutos não ensacados) & $127,1 \mathrm{ab}$ & 103,1 & $70,4 \mathrm{~b}$ & $90,9 \mathrm{~b}$ & 119,9 \\
\hline Média & 149,7 & 117,0 & 123,1 & 103,2 & 134,8 \\
\hline CV (\%) & 21,1 & 13,7 & 24,6 & 10,2 & 12,0 \\
\hline
\end{tabular}

${ }^{1}$ Médias não seguidas de mesma letra minúscula na coluna, diferem entre si pelo teste de Tukey a 5\% de probabilidade de erro.

ns =não-significativo.

Na M-11/00 e na M-13/00, o ensacamento dos frutos proporcionou aumento máximo no peso, em relação aos frutos não ensacados, de 105 e 20\%, respectivamente. Estes resultados mostram que o uso do ensacamento e a manutenção das embalagens até próximo da colheita favorecem o crescimento dos frutos, possivelmente devido ao menor ataque de insetos-praga, principalmente a mosca-das-frutas. Os mesmos resultados também também observados por SANTOS (2005) e por SANTOS \& WAMSER (2006), para as cultivares "Fuji Suprema" e "Royal Gala”. Este inseto pode atacar desde frutos muito pequenos até frutos em fase de maturação. Em frutos imaturos, o ataque provoca deformação, devido à punctura feita pelas fêmeas no momento da oviposição. Os insetos não completam o ciclo em frutos imaturos, devido ao teor de acidez. Quando o ataque ocorre em frutos maduros, as larvas se alimentam da polpa, fazendo galerias nos frutos, afetando conseqüentemente o peso e o tamanho dos frutos atacados.
Comparando-se os dois tipos de embalagens, não foram observadas diferenças entre elas para tamanho e peso de frutos em nenhum dos genótipos estudados, mostrando apresentarem eficiência semelhante.

Cor de fundo da epiderme dos frutos

Somente na cv. "Royal Gala” e na seleção MR-11/90 houve diferenças entre os tratamentos para cor de fundo dos frutos. Para esses dois genótipos, apenas quando foi utilizada a embalagem de papel manteiga parafinado retirada na colheita, houve redução nos valores de cor de fundo. Já para a seleção MR-11/90, o maior valor de cor de fundo foi observado com a retirada da embalagem de polipropileno microperfurado aos 15 dias antes da colheita. Porém, esse valor não diferiu ao do tratamento de retirada da embalagem de papel manteiga parafinado aos 15 dias antes da colheita (Tabela 2). Esses resultados mostram que o ensacamento de frutos por longo tempo pode 
Tabela 2 - Cor de fundo de frutos de diferentes genótipos de macieira em função do tipo de embalagem utilizada no ensacamento e da época de desensacamento.

\begin{tabular}{|c|c|c|c|c|c|}
\hline \multirow{2}{*}{ Tratamentos $^{1}$} & Fuji Suprema & Royal Gala & M-11/00 & $\mathrm{M}-13 / 00$ & MR-11/90 \\
\hline & \multicolumn{5}{|c|}{ Cor de fruto da epiderme dos frutos* } \\
\hline \multicolumn{6}{|l|}{ Papel manteiga parafinado branco } \\
\hline 15 dias antes da colheita & $4,0^{\mathrm{ns}}$ & $3,5 a b^{1}$ & $4,0^{\mathrm{ns}}$ & $4,0^{\mathrm{ns}}$ & $3,8 a b^{1}$ \\
\hline 7 dias antes da colheita & 4,0 & $3,4 \mathrm{ab}$ & 3,9 & 4,0 & 3,5 bc \\
\hline Dia da colheita & 4,0 & $3,3 \mathrm{~b}$ & 3,9 & 4,0 & $3,3 \mathrm{c}$ \\
\hline \multicolumn{6}{|c|}{ Polipropileno microperfurado transparente } \\
\hline 15 dias antes da colheita & 4,0 & $3,9 a b$ & 4,0 & 4,0 & 3,9 a \\
\hline 7 dias antes da colheita & 4,0 & $3,8 a b$ & 4,0 & 4,0 & $3,7 \mathrm{~b}$ \\
\hline Dia da colheita & 4,0 & $3,7 \mathrm{ab}$ & 4,0 & 4,0 & $3,7 \mathrm{~b}$ \\
\hline Controle (frutos não ensacados) & 4,0 & $4,0 \mathrm{a}$ & 4,0 & 4,0 & $3,8 \mathrm{ab}$ \\
\hline Média & 4,0 & 3,6 & 3,9 & 4,0 & 3,7 \\
\hline CV (\%) & 0,0 & 11,5 & 1,5 & 0,0 & 6,5 \\
\hline
\end{tabular}

${ }^{1}$ Médias não seguidas de mesma letra minúscula na coluna, diferem entre si pelo teste de Tukey a 5\% de probabilidade de erro.

${ }^{\mathrm{ns}}=$ não-significativo.

* Escala de cores de 1 a 5 para cultivares e seleções dos grupos “Gala” e "Fuji”.

alterar o padrão de cor de fundo, retardando o amarelecimento, induzindo à colheita de frutos antes da maturação.

Comparando os tipos de embalagens, observou-se uma tendência de maiores valores de cor de fundo para frutos ensacados com embalagem de polipropileno microperfurado (Tabela 2). Possivelmente, isso se deve à melhor passagem de luz e à temperatura no interior de embalagens de prolipropileno em relação à de papel manteiga parafinado. Estes resultados já haviam sido observados nas cultivares "Royal Gala" e "Fuji Suprema" por SANTOS (2005) e por SANTOS \& WAMSER (2006). A macieira é uma espécie que exige alta densidade de fluxo radiante, principalmente na fase de maturação, pois a luz solar influencia na pigmentação da epiderme, tornando os frutos mais vermelhos. No presente estudo, verificou-se que frutos ensacados com embalagem de polipropileno microperfurado foram mais favorecidos pela maior penetração de luz. TELLES et al. (2004) estudaram o efeito de embalagens de papel jornal grampeado, papel pardo e papel manteiga na qualidade de frutos de pessegueiro "Coral" e verificaram que a coloração dos frutos foi influenciada pelo tipo de embalagem utilizada, sendo que os frutos do tratamento-controle (não ensacados) e os frutos ensacados com papel manteiga apresentaram melhor aspecto, maior uniformidade e coloração mais avermelhada.
Russeting na epiderme dos frutos

A ocorrência de russeting foi observada em todos os genótipos, com exceção da seleção M-11/00. Somente na seleção $M-13 / 00$, houve diferenças significativas entre os tratamentos, na qual a retirada da embalagem de polipropileno microperfurado aos sete dias antes da colheita proporcionou maior percentagem de frutos com "russeting". No entanto, houve diferença somente do ensacamento com embalagem de papel manteiga parafinado retirada na colheita (Tabela 3). Estes resultados não permitem distinguir nenhum efeito do ensacamento de frutos ou do tipo e época de retirada da embalagem sobre os danos por "russeting". CAMILO \& DENARDI (2006) comentam que a presença de russeting é um fator depreciativo da qualidade dos frutos, prejudicando sua comercialização. FAORO \& MONDARDO (2004) verificaram que o ensacamento de frutos de pereira japonesa "Housui” logo após a plena floração induziu melhor qualidade externa dos frutos, pois o período mais crítico para o desenvolvimento de "russeting" ocorre nas primeiras fases de crescimento do fruto. Embalagens de papel manteiga, preferencialmente parafinados e de coloração escura, protegeram e melhoraram a aparência dos frutos de pêra.

Queimadura na epiderme dos frutos pelo sol

A queimadura de frutos pelo sol foi influenciada pelo tipo de embalagem utilizada no ensacamento. No ensacamento com papel manteiga parafinado, não houve queimaduras de sol nas 
Tabela 3 - Russeting e queimadura de frutos em diferentes genótipos de macieira em função do tipo de embalagem utilizada no ensacamænto e da época de desensacamento.

\begin{tabular}{|c|c|c|c|c|c|}
\hline \multirow[t]{2}{*}{ Tratamentos } & Fuji Suprema & Royal Gala & $\mathrm{M}-11 / 00$ & $\mathrm{M}-13 / 00$ & MR-11/90 \\
\hline & \multicolumn{5}{|c|}{ “Russeting” (\%) } \\
\hline \multicolumn{6}{|l|}{ Papel manteiga parafinado branco } \\
\hline 15 dias antes da colheita & $36,7^{\mathrm{ns}}$ & $49,6^{\mathrm{ns}}$ & - & $21,9 \mathrm{ab}^{1}$ & $41,1^{\mathrm{ns}}$ \\
\hline 7 dias antes da colheita & 38,0 & 32,7 & - & $9,0 \mathrm{ab}$ & 37,8 \\
\hline Dia da colheita & 52,1 & 42,1 & - & $3,4 \mathrm{~b}$ & 24,9 \\
\hline \multicolumn{6}{|c|}{ Polipropileno microperfurado transparente } \\
\hline 15 dias antes da colheita & 20,7 & 50,5 & - & $16,6 \mathrm{ab}$ & 41,9 \\
\hline 7 dias antes da colheita & 59,2 & 13,0 & - & 32,9 a & 21,0 \\
\hline Dia da colheita & 38,4 & 34,2 & - & $18,2 \mathrm{ab}$ & 23,8 \\
\hline Controle (frutos não ensacados) & 36,0 & 33,7 & - & $10,9 \mathrm{ab}$ & 23,8 \\
\hline Média & 40,1 & 36,5 & - & 16,1 & 30,6 \\
\hline \multirow[t]{2}{*}{ CV (\%) } & 69,0 & 68,0 & - & 85,7 & 51,7 \\
\hline & \multicolumn{5}{|c|}{ Queimadura (\%) } \\
\hline \multicolumn{6}{|l|}{ Papel manteiga parafinado branco } \\
\hline 15 dias antes da colheita & $0,0 \mathrm{~b}$ & $0,0 \mathrm{~b}$ & $0,0^{\mathrm{ns}}$ & $1,0^{\mathrm{ns}}$ & $3,9 \mathrm{c}$ \\
\hline 7 dias antes da colheita & $0,0 \mathrm{~b}$ & $0,0 \mathrm{~b}$ & 0,0 & 3,2 & $2,6 \mathrm{c}$ \\
\hline Dia da colheita & $0,0 \mathrm{~b}$ & $2,5 \mathrm{ab}$ & 0,9 & 0,7 & 17,6 abc \\
\hline \multicolumn{6}{|c|}{ Polipropileno microperfurado transparente } \\
\hline 15 dias antes da colheita & $9,0 \mathrm{ab}$ & $4,1 \mathrm{ab}$ & 1,0 & 2,5 & $28,0 \mathrm{ab}$ \\
\hline 7 dias antes da colheita & 32,0 a & 13,5 a & 0,7 & 2,8 & $22,4 \mathrm{abc}$ \\
\hline Dia da colheita & $25,0 \mathrm{ab}$ & $6,8 \mathrm{ab}$ & 4,9 & 2,2 & 35,2 a \\
\hline Controle (frutos não ensacados) & $12,7 \mathrm{ab}$ & $0,0 \mathrm{~b}$ & 0,0 & 0,0 & 7,7 bc \\
\hline Média & 11,2 & 3,8 & 1,1 & 1,8 & 16,8 \\
\hline CV (\%) & 156,7 & 190,9 & 288,9 & 158,4 & 97,7 \\
\hline
\end{tabular}

${ }^{1}$ Médias não seguidas de mesma letra minúscula na coluna, diferem entre si pelo teste de Tukey a 5\% de probabilidade de erro.

ns $=$ não-significativo.

cultivares "Fuji Suprema” e "Royal Gala” e na seleção M-11/00, quando os sacos foram retirados aos sete e 15 dias antes da colheita. E, na retirada na colheita, a percentagem de frutos com queimaduras foi baixa. Comparando-se os diferentes genótipos, a maior incidência de queimaduras foi observada na seleção MR-11/90, independentemente da embalagem utilizada (Tabela 3). Confrontando-se os dados dos tratamentos de ensacamento com os do controle, observou-se que a embalagem de papel manteiga parafinado, em geral, protegeu os frutos contra queimaduras; já a embalagem de polipropileno microperfurado induziu este dano. A embalagem de polipropileno microperfurado intensifica o amarelecimento da cor de fundo dos frutos em relação às de papel manteiga parafinado; no entanto, aumenta a queimadura de frutos pela radiação solar. De acordo com SANTOS (2005) e SANTOS \& WAMSER (2006), quando a embalagem de polipropileno microperfurado se encontra muito aderida à epiderme dos frutos, ocorrem queimaduras devido a maior penetração da radiação solar.

\section{CONCLUSÕES}

Em alguns genótipos, o não-ensacamento de frutos promove menor diâmetro e peso médio dos frutos. A permanência das embalagens nos frutos até a colheita altera o padrão de cor de fundo, retardando o amarelecimento, induzindo à colheita antes da maturação.

O ensacamento de frutos não influenciou a incidência de russeting. O uso da embalagem de polipropileno microperfurado transparente estimula a queimadura de frutos em relação à embalagem de papel manteiga parafinado e ao não ensacamento de frutos. 


\section{REFERÊNCIAS}

ABPM. Informações estatísticas. Capturado em $10 \mathrm{dez}$ 2004. Online. Disponível na Internet http://www.abpm.org.br/ informações.htm.

ABBOT, J.A. Quality measurement of fruits and vegetables. Postharvest Biology and Technology, v.15, n.1, p.207-225, 1999.

ARGENTA, L.C. Índice de cores para maçãs “Gala”. Florianópolis: Epagri, 2004a. 1p.

ARGENTA, L.C. Índice de cores para maçãs “Fuji”. Florianópolis: Epagri, 2004b. 1p.

ALMEIDA, G.V.B. de; ALVES, A.A. Mercado de maçã: situação atual, ameaças, oportunidades e estratégias para o futuro. In: SEMINÁRIO NACIONAL SOBRE FRUTICULTURA DE CLIMA TEMPERADO, 7., 2006, São Joaquim, SC. Resumos... São Joaquim: Epagri, 2006. V.1. 72p. p.56-65.

BASSO, C. Distúrbios fisiológicos. In: EPAGRI. A cultura da macieira. Florianópolis: Epagri, 2006. Cap.17, p.609-636.

CAMILO, A.P.; DENARDI, F. Cultivares: descrição e comportamento no sul do Brasil. In: EPAGRI. A cultura da macieira. Florianópolis: Epagri, 2006. Cap.5, p.113-168.

FAO. Statistical databases. Capturado em 20 jul. 2006. Online. Disponível na Internet http://www.fao.org/waicent/ portal/statistics_em.asp.
FAORO, I.D. Raleio e ensacamento de frutos. In: CURSO SOBRE A CULTURA DA PEREIRA, 3., 2001, Caçador, SC. Trabalhos apresentados... Caçador: Epagri, 2001. V.1. 146p. p.79-83.

FAORO. I.D. Efeito do ensacamento na aparência externa da maçã cv. Condessa. In: CONGRESSO BRASILEIRO DE FRUTICULTURA, 18., 2004, Florianópolis, SC. Anais... Florianópolis: Epagri, 2004. 1 CD.

FAORO, I.D.; MONDARDO, M. Ensacamento de frutos de pereira cv. Housui. Revista Brasileira de Fruticultura, v.26, n.1, p.86-88, 2004.

PANDOLFO, C. et al. Atlas climatológico do estado de Santa Catarina. Florianópolis: Epagri, 2002. 1 CD.

PETRI, J.L. et al. Tratos culturais: ensacamento de frutos. In: EPAGRI. Nashi, a pêra japonesa. Florianópolis: Epagri, 2001. Cap.7, p.204-206.

SANTOS, J.P. Ensacamento de frutos como alternativa para o controle de pragas em pomar orgânico de macieira. In: CONGRESSO BRASILEIRO DE AGROECOLOGIA, 3., 2005, Florianópolis, SC. Anais... Florianópolis: Epagri, 2005. 1 CD.

SANTOS, J.P.; WAMSER, A.F. Efeito do ensacamento de frutos sobre danos causados por fatores bióticos e abióticos em pomar orgânico de macieira. Revista Brasileira de Fruticultura, v.28, n.2, p.168-171, 2006.

TELLES, C.A. et al. Produção e qualidade de pêssegos ensacados da cultivar Coral. Revista Agropecuária Catarinense, v.17, n.1, p.83-86, 2004. 